\title{
Relationship of aberrant DNA hypermethylation of $C H F R$ with sensitivity to taxanes in endometrial cancer
}

\author{
MEGUMI YANOKURA*, KOUJI BANNO*, MAKIKO KAWAGUCHI, NOBUMARU HIRAO, \\ AKIRA HIRASAWA, NOBUYUKI SUSUMU, KATSUMI TSUKAZAKI and DAISUKE AOKI \\ Department of Obstetrics and Gynecology, Keio University School of Medicine, Tokyo, Japan
}

Received August 31, 2006; Accepted October 9, 2006

\begin{abstract}
The relationship of aberrant DNA hypermethylation of cell cycle checkpoint genes with the sensitivity of cancer cells to anticancer drugs is a question of current interest. In this study, we investigated the relationship between aberrant hypermethylation of the CHFR (checkpoint with forkheadassociated and ring finger) mitotic checkpoint gene and sensitivity to taxanes in endometrial cancer. Methylation-specific PCR (MSP) indicated aberrant hypermethylation of CHFR in $12.0 \%(6 / 50)$ of endometrial cancer specimens, and suggested that aberrant hypermethylation is significantly more frequent in poorly differentiated adenocarcinoma $(\mathrm{G} 3)(\mathrm{p}<0.05)$. Of six culture cell lines, SNG-II and HEC108 cells showed aberrant hypermethylation and reduced expression of $C H F R$. These cells had high sensitivity to taxanes but became resistant after demethylation. Cancer specimens with aberrant hypermethylation of CHFR also exhibited high sensitivity to taxanes. To our knowledge, this study is the first to examine aberrant hypermethylation of $C H F R$ in endometrial cancer, and our results suggest that the methylation status of $C H F R$ may be a new molecular index that will allow design of personalized treatment in endometrial cancer. This may be particularly important in poorly differentiated adenocarcinoma (G3), which is known to have a poor prognosis.
\end{abstract}

\section{Introduction}

Recent studies have shown that aberrant DNA hypermethylation of cell cycle checkpoint genes in cancer cells has a major effect on specific anticancer drugs $(1,2)$. The $C H F R$ (checkpoint with forkhead-associated and ring finger) mitotic

Correspondence to: Dr Kouji Banno, Department of Obstetrics and Gynecology, Keio University School of Medicine, Shinanomachi 35, Shinjuku-ku, Tokyo 160-8582, Japan

E-mail: kbanno@sc.itc.keio.ac.jp

${ }^{*}$ Contributed equally

Key words: CHFR, endometrial cancer, DNA hypermethylation, taxane, chemosensitivity checkpoint gene is located in $12 \mathrm{q} 24.33$ and has the function of delaying chromatin condensation and progression to the mitotic phase (3). The CHFR protein has a forkhead-associated domain in the N-terminal region and a finger domain in the central region; these two domains act as a sensor for mitotic stress and therefore function as a cell cycle $M$ phase checkpoint. Upon detection of mitotic stress in a cell, CHFR action causes arrest of the cell cycle in G2 phase to allow repair of damaged DNA (G2 arrest).

Taxanes are anticancer agents that act in $\mathbf{M}$ phase as microtubule depolymerization inhibitors. Upon administration of a taxane to cancer cells, those cells with normal CHFR develop G2 arrest and repair damaged DNA, thereby exhibiting resistance to taxanes. In contrast, cells with inactivated $C H F R$ due to aberrant hypermethylation proceed with the cell cycle due to failed detection of damaged DNA and subsequently cannot go on to normal cell division, leading to mitotic catastrophe and cell death; i.e., these cells show high sensitivity to taxanes. Given this background, the methylation status of $C H F R$ is likely to be a highly sensitive molecular index for taxane sensitivity of cancer cells.

A relationship between aberrant hypermethylation of CHFR and sensitivity to taxanes has been reported in colon and gastric cancer cells in culture $(2,4)$, but not in endometrial cancer. Therefore, we investigated this relationship in endometrial cancer, with the goal of establishing a molecular index that might lead to personalized treatment strategies for endometrial cancer.

\section{Materials and methods}

Subjects and specimens for biopsy. The subjects were 69 patients who gave informed consent for collection of endometrial specimens ( 9 of normal endometrium, 10 of atypical endometrial hyperplasia and 50 of endometrial cancer). Cells obtained from the tissue specimens were examined by liquidbased cytology using the ThinPrep System (Cytyc Corp., Boxborough, MA) with preservation fluid (PreservCyt Solution, Cytyc Corp.) (5). A pathological diagnosis of the endometrial tissue was consistent with cytology results for all 69 subjects. Of the 9 patients with a normal endometrium, 5 were in the secretory phase and 4 were in the proliferative phase, and of the 50 patients with endometrial cancer, 42 had ovarian endometrioid adenocarcinoma $(\mathrm{G} 1,20 ; \mathrm{G} 2,12 ; \mathrm{G} 3,10)$ and 8 had adenosquamous carcinoma. The grade of histo- 
Table I. Primer sequences used in MSP and RT-PCR analyses.

\begin{tabular}{llllll}
\hline $\begin{array}{l}\text { Gene } \\
\text { name }\end{array}$ & \multicolumn{1}{c}{$\begin{array}{c}\text { PCR } \\
\text { analysis }\end{array}$} & \multicolumn{1}{c}{ Sense } & Antisense & $\begin{array}{c}\text { Size } \\
(\mathrm{bp})\end{array}$ & $\begin{array}{c}\text { Annealing } \\
\text { temperature }\left({ }^{\circ} \mathrm{C}\right)\end{array}$ \\
\hline CHFR & $\begin{array}{l}\text { Methylated } \\
\text { Unmethylated }\end{array}$ & GTCGGGTCGGGGTTC & CCCAAAACTACGACGACG & 150 & 60 \\
& ATATATGGTGTTGATT & TCAACTAATCCACAAAACA & 206 & 53 \\
CHFR & RT-PCR & TGGAACAGTGATTAACAAGC & AGGTATCTTTGGTCCCATGG & 206 & 55 \\
$\beta$-actin & RT-PCR & TTATTTGAGCTTTGGTTCTG & CTCCTTAATGTCACGCACGATTCC & 303 & 50 \\
\hline
\end{tabular}

logical differentiation (G1-G3) and the cancer stage at surgery were determined based on the Guidelines for Endometrial Cancer published by the Japan Society of Obstetrics and Gynecology.

Culture cell lines. Six cell strains were used: HEC108 (a human endometrial cancer-derived culture cell line supplied by Dr Hiroyuki Kuramoto), HOOUA and HHUA (supplied by Dr Isamu Ishiwata) and SNG-II, HEC1B and KLE. KLE cells were cultured in a DMEM/F12 (1:1) medium (Gibco BRL, Rockville, MD, USA) supplemented with $10 \%$ fetal bovine serum (FBS) (Sanko Junyaku Co., Ltd., Tokyo, Japan), and the other cells were cultured in 10\% FBS-supplemented F12 medium (Sigma, St. Louis, MO, USA). The cells were incubated in a $10-\mathrm{cm}$ dish under $5 \% \mathrm{CO}_{2}$ at $37^{\circ} \mathrm{C}$.

DNA extraction and methylation-specific PCR (MSP) analysis of $C H F R$. DNA was extracted from 69 endometrial specimens and 6 endometrial cancer-derived cell lines using liquidbased cytology with a GetPure DNA Kit (Dojindo Molecular Technologies, Inc., Kumamoto, Japan). Distilled water was added to $1 \mu \mathrm{g}$ of the extracted DNA up to a volume of $50 \mu 1$, $5.5 \mu 1$ of $3 \mathrm{~N} \mathrm{NaOH}$ solution was added, and after mixing the solution was incubated at $37^{\circ} \mathrm{C}$ for $15 \mathrm{~min}$. Following this, $520 \mu \mathrm{l}$ of $3 \mathrm{M}$ sodium bisulfate (Sigma), which was prepared at $\mathrm{pH} 5.5$ with $30 \mu \mathrm{l}$ of $10 \mathrm{mM}$ hydroquinone (Sigma) and $10 \mathrm{~N} \mathrm{NaOH}$, was added to the solution. After mixing in an upturned position to prevent vaporization, the solution was overlaid with mineral oil and incubated at $50^{\circ} \mathrm{C}$ overnight. Next, $1 \mathrm{ml}$ of clean-up resin (Promega Corp., Madison, WI, USA) was added to the lower layer, and the resulting solution was mixed in an upturned position and then injected into a column. After rinsing with $2 \mu 1$ of $80 \%$ isopropanol, the column was centrifuged at $15,000 \mathrm{rpm}$ for $3 \mathrm{~min}$ to remove isopropanol completely, after which $50 \mu 1$ of distilled water $\left(70^{\circ} \mathrm{C}\right)$ was added directly to the column, and the column was centrifuged at 15,000 rpm for 2 min to extract DNA adsorbed on the column. Then, $5.5 \mu 1$ of $2 \mathrm{~N} \mathrm{NaOH}$ was added to the resulting DNA solution, and after mixing the solution was incubated at $37^{\circ} \mathrm{C}$ for $20 \mathrm{~min}$, after which $66 \mu 1$ of $5 \mathrm{~N}$ ammonium acetate and $243 \mu 1$ of $95 \%$ ethanol were added. The solution was then incubated at $-80^{\circ} \mathrm{C}$ for $1 \mathrm{~h}$ and centrifuged at 15,000 rpm for $30 \mathrm{~min}$ to precipitate DNA. Approximately, $50 \mu 1$ of the supernatant was left in the tube, and the rest of the supernatant was collected, mixed with $1 \mathrm{ml}$ of $70 \%$ ethanol, and then centrifuged at 15,000 rpm for $30 \mathrm{~min}$ to rinse the DNA. The precipitated DNA was air-dried and dissolved in $20 \mu 1$ of distilled water; $2 \mu 1$ of this solution was used as the MSP template solution. AmpliTaq Gold and 10X PCR buffer/ $\mathrm{MgCl}_{2}$ with dNTP (Applied Biosystems, Foster City, CA, USA) was used in the PCR analysis, and DNA was analyzed using a GeneAmp PCR System 9700 (Applied Biosystems). The PCR conditions for other genes and primer sequences are shown in Table I. DNA extracted from the culture cell lines was also used in MSP analysis of CHFR.

Statistical analysis. Correlations of aberrant DNA hypermethylation of $C H F R$ with the grade of histological differentiation and the cancer stage at surgery were analyzed using the $\chi^{2}$ test and Mann-Whitney test, respectively. Correlation of aberrant DNA hypermethylation of $C H F R$ with patient age was also examined, after establishing that the groups of patients with and without aberrant hypermethylation had a normal age distribution. The Mann-Whitney test was used to examine whether the population medians of the two independent groups differed significantly.

RNA extraction and expression analysis of CHFR using $R T-P C R$. Total-RNA was extracted from 6 endometrial cancerderived cell lines using a RNeasy mini-Kit (Qiagen, Valencia, CA, USA). cDNA was synthesized with $1 \mu \mathrm{g}$ of total-RNA using a SuperScript II Reverse Transcriptase kit (Invitrogen, Carlsbad, CA, USA). Synthesized 1st strand cDNA (1 $\mu \mathrm{l})$ was used as a template solution in RT-PCR analysis of CHFR expression. AmpliTaq Gold and 10X PCR buffer/ $\mathrm{MgCl}_{2}$ with dNTP (Applied Biosystems) was used in the PCR analysis, and DNA was analyzed using a GeneAmp PCR System 9700 (Applied Biosystems). The PCR conditions and primer sequences are shown in Table I.

Demethylation. SNG-II cells, which are endometrial cancerderived cells with aberrant hypermethylation of $C H F R$, were plated on a $10-\mathrm{cm}$ dish at $10^{6}$ cells/dish and incubated for $72 \mathrm{~h}$. A demethylating agent, 5-aza-dC (Sigma), was then added until its final concentration in the culture medium was $1 \mu \mathrm{M}$. Forty-eight hours after the first addition 5-aza-dC was added again, and DNA and RNA were extracted 24 and $72 \mathrm{~h}$ after the second addition, respectively.

Cell cycle analysis using flow cytometry. SNG-II and KLE cells, which are both endometrial cancer-derived cell lines, were plated on a $10-\mathrm{cm}$ dish at $5 \times 10^{5}$ cell/dish and incubated 

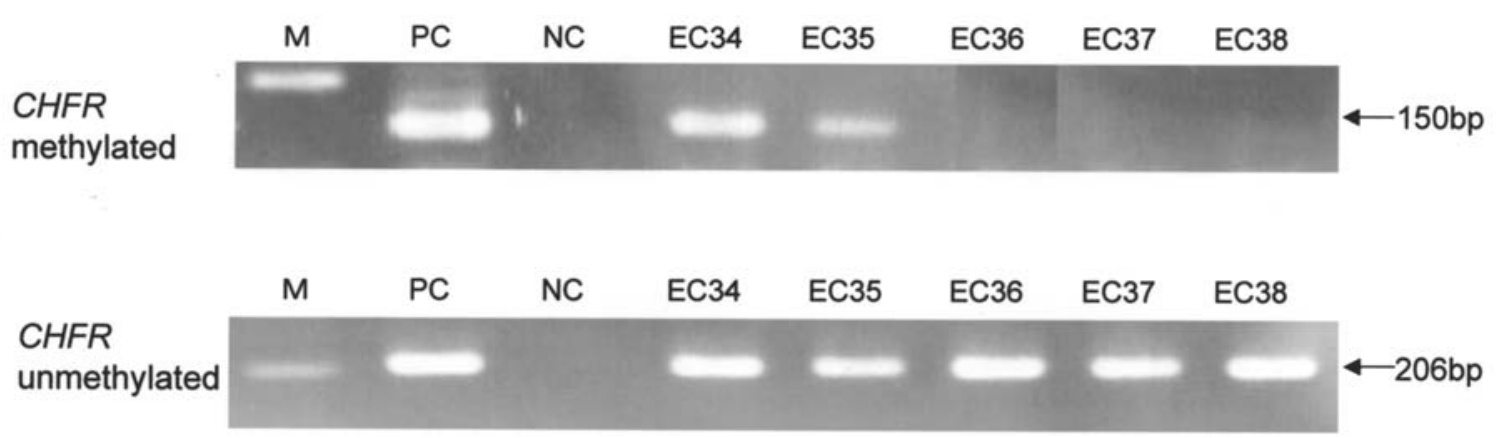

Figure 1. MSP analysis of CHFR in endometrial cancer cells obtained using cytology. MSP analysis was conducted with DNA extracted from specimens of endometrial cancer. Bands due to aberrant hypermethylation are found in lanes EC34 and EC35. M, marker; PC, positive control; NC, negative control; EC, endometrial cancer.

to $80 \%$ confluence. Paclitaxel (Bristol-Myers Squibb Co., NY, USA) was then added until its final concentration in the culture medium was $1.0 \mu \mathrm{g} / \mathrm{ml}$. Forty-eight hours later, the cells were treated with trypsin, washed twice with PBS, and then centrifuged at 15,000 rpm for $5 \mathrm{~min}$. The supernatant was removed and the cell pellet was washed with $500 \mu 1$ of PBS. The vortexed cells were combined with $1 \mathrm{ml}$ of $100 \%$ cold ethanol and then incubated at room temperature for $30 \mathrm{~min}$ for fixation. After rinsing twice with PBS and removing the supernatant, $500 \mu 1$ of RNase was added to the cell pellet and the mixture was incubated at room temperature for $20 \mathrm{~min}$. After a further addition of $500 \mu 1$ of propidium iodide (PI), the cells were strained with a cell strainer and cell cycle status was determined using an EpicsXL MCL flow cytometer (Beckman Coulter Inc., Fullerton, CA, USA).

Anticancer drug-sensitivity test. A collagen gel dropletembedded culture drug-sensitivity test (CD-DST) was performed using 6 endometrial cancer-derived cell lines and 12 of 50 specimens of endometrial cancer (6). The culture cells and specimens were treated with a cell-dispersing enzyme, EZ (Nitta Gelatin Inc., Tokyo, Japan), for $2 \mathrm{~h}$ and centrifuged. The cells were preincubated in a collagen gel flask for $24 \mathrm{~h}$ and the living cells that attached to the collagen gel were collected. Cellmatrix Type CD solution was added to these cells, and then 3 drops of a $30-\mu 1 /$ drop collagen gel cell suspension were placed in a 6-well plate. The cell suspension was left to stand for $1 \mathrm{~h}$ in an incubator under $5 \% \mathrm{CO}_{2}$ at $37^{\circ} \mathrm{C}$, and after gelation the medium was doubled to $4 \mathrm{ml} /$ well and anticancer drugs were added. Four anticancer drugs, cisplatin, doxorubicin, paclitaxel and docetaxel, were used at final concentrations of 2.0,0.02, 1.0 and $0.1 \mu \mathrm{g} / \mathrm{ml}$, respectively. Twenty-four hours after drug administration, the cells were washed to remove the anticancer drugs and then incubated without serum for 7 days under $5 \% \mathrm{CO}_{2}$ at $37^{\circ} \mathrm{C}$. After staining with Neutral Red, the cells were fixed with formalin and dried, and cell images were processed using an image analyzer. In the CD-DST, drug sensitivity is assessed using the ratio $(\mathrm{T} / \mathrm{C})$ of the number of living cells cultured in a solution containing anticancer drug $(\mathrm{T})$ to that of control cells cultured in a solution without anticancer drug (C).

Expression analysis of CHFR protein. Specimens of endometrial cancer (G3) from 4 patients with aberrant hypermethy- lation of CHFR were embedded with OCT compound and frozen in liquid nitrogen. Cryostat-sliced sections were applied to slides and fixed with $100 \%$ ethanol, and the slides were incubated at $4{ }^{\circ} \mathrm{C}$ overnight with primary antibody (anti-CHFR antibody; Santa Cruz, Delaware, CA, USA) diluted 100-fold with $1 \%$ BSA in PBS. After rinsing three times with PBS, the slides were incubated with secondary antibody (biotin-labeled anti-goat $\mathrm{IgG}$ ) at room temperature for $30 \mathrm{~min}$, and after three further rinses with PBS the slides were incubated with ABC (avidin-biotin peroxidase) complex at room temperature for $30 \mathrm{~min}$. After further rinsing three times with PBS, the slides were treated with $0.2 \mathrm{mg} / \mathrm{ml}$ diaminobenzidine (DAB) for about $5 \mathrm{~min}$ as a color reaction. After rinsing twice with PBS, the slides were treated with hematoxylin solution for nuclear staining, then dehydrated and enclosed, and observed microscopically. Immunohistochemical data for staining of CHFR protein were assessed using the following criteria: specimens with $30 \%$ or more of stained tumor cells were considered positive, and specimens with $<30 \%$ of tumor cells showing staining were considered negative.

\section{Results}

Partial results of MSP analysis of endometrial cancer cells obtained using liquid-based cytology are shown in Fig. 1. Endometrial cancer specimens had a $12.0 \%$ (6/50) frequency of aberrant hypermethylation of the promoter region of $C H F R$, whereas specimens of atypical endometrial hyperplasia and normal endometrial cells in the proliferative and secretory phases showed no aberrant hypermethylation of the CHFR promoter region (Fig. 1, Tables II and III).

Correlations of aberrant DNA hypermethylation of the CHFR promoter with clinicopathological factors were examined in endometrial cancer patients. The frequency of aberrant hypermethylation in G3 adenocarcinoma was significantly higher than in $\mathrm{G} 1$ adenocarcinoma $(\mathrm{p}<0.05)$. Aberrant DNA hypermethylation is also generally thought to increase with age, but no significant difference in mean age was found between patients with and without aberrant hypermethylation of CHFR. Therefore, these data do not indicate that aberrant hypermethylation occurs more frequently in elderly patients with endometrial cancer (Table IV).

Of the 6 culture cell lines derived from endometrial cancer, SNG-II and HEC108 cells showed aberrant hypermethylation 
Table II. Frequency of aberrant DNA hypermethylation of CHFR in specimens of endometrial cancer.

\begin{tabular}{|c|c|c|c|c|c|}
\hline No. & Age & Tissue type & Stage & Differentiation & CHFR \\
\hline $\mathrm{EC} 1$ & 52 & EM & $\mathrm{Ib}$ & G3 & $\mathrm{U}$ \\
\hline $\mathrm{EC} 2$ & 50 & EM & $\mathrm{Ia}$ & G1 & $\mathrm{U}$ \\
\hline EC3 & 51 & EM & IIIc & G1 & $\mathrm{U}$ \\
\hline $\mathrm{EC} 4$ & 54 & AS & IIIc & G3 & M \\
\hline EC5 & 51 & EM & Ia & G1 & $\mathrm{U}$ \\
\hline EC6 & 61 & EM & $\mathrm{Ib}$ & G1 & $\mathrm{U}$ \\
\hline EC7 & 70 & EM & IIIc & G2 & $\mathrm{U}$ \\
\hline EC8 & 61 & EM & $\mathrm{IIb}$ & G1 & $\mathrm{U}$ \\
\hline EC9 & 62 & $\mathrm{AS}$ & IIIa & G2 & $\mathrm{U}$ \\
\hline EC10 & 40 & EM & IIa & G1 & $\mathrm{U}$ \\
\hline EC11 & 59 & EM & IIa & G3 & $\mathrm{U}$ \\
\hline $\mathrm{EC} 12$ & 57 & EM & $\mathrm{Ib}$ & G3 & $\mathrm{U}$ \\
\hline EC13 & 80 & EM & IIIc & G3 & $\mathrm{U}$ \\
\hline EC14 & 54 & AS & $\mathrm{Ib}$ & G1 & $\mathrm{U}$ \\
\hline $\mathrm{EC} 15$ & 53 & EM & $\mathrm{Ib}$ & G3 & $\mathrm{U}$ \\
\hline EC16 & 42 & EM & $\mathrm{IIb}$ & G1 & $\mathrm{U}$ \\
\hline $\mathrm{EC} 17$ & 71 & EM & IIIc & G3 & $\mathrm{U}$ \\
\hline EC18 & 60 & EM & $\mathrm{Ib}$ & G1 & $\mathrm{U}$ \\
\hline EC19 & 57 & EM & IIIa & G2 & $\mathrm{U}$ \\
\hline EC20 & 71 & EM & IIa & G1 & $\mathrm{U}$ \\
\hline $\mathrm{EC} 21$ & 37 & EM & IIa & G2 & $\mathrm{U}$ \\
\hline $\mathrm{EC} 22$ & 47 & EM & $\mathrm{IIIb}$ & G1 & $\mathrm{U}$ \\
\hline $\mathrm{EC} 23$ & 67 & EM & Ic & G2 & $\mathrm{M}$ \\
\hline $\mathrm{EC} 24$ & 53 & EM & Ia & G1 & $\mathrm{U}$ \\
\hline EC25 & 69 & EM & IIIc & G2 & $\mathrm{U}$ \\
\hline EC26 & 55 & EM & IIIc & G2 & $\mathrm{U}$ \\
\hline $\mathrm{EC} 27$ & 54 & EM & $\mathrm{Ia}$ & G1 & $\mathrm{U}$ \\
\hline EC28 & 63 & EM & Ia & G1 & $\mathrm{U}$ \\
\hline EC29 & 41 & EM & $\mathrm{Ib}$ & G1 & $\mathrm{U}$ \\
\hline EC30 & 62 & $\mathrm{AS}$ & $\mathrm{Ib}$ & G1 & $\mathrm{U}$ \\
\hline EC31 & 58 & EM & $\mathrm{Ib}$ & G2 & $\mathrm{U}$ \\
\hline EC32 & 56 & EM & IIIc & G3 & $\mathrm{M}$ \\
\hline EC33 & 71 & EM & $\mathrm{Ib}$ & G2 & $\mathrm{U}$ \\
\hline EC34 & 53 & $\mathrm{AS}$ & $\mathrm{Ib}$ & G3 & M \\
\hline EC35 & 50 & EM & IIIa & G3 & $\mathrm{M}$ \\
\hline EC36 & 42 & $\mathrm{AS}$ & IIIc & G3 & $\mathrm{U}$ \\
\hline EC37 & 55 & EM & Ic & G3 & $\mathrm{U}$ \\
\hline EC38 & 34 & $\mathrm{AS}$ & IIIc & G1 & $\mathrm{U}$ \\
\hline EC39 & 61 & EM & Ic & G1 & $\mathrm{U}$ \\
\hline $\mathrm{EC} 40$ & 61 & EM & Ic & G1 & $\mathrm{U}$ \\
\hline EC41 & 61 & EM & $\mathrm{Ib}$ & G1 & $\mathrm{U}$ \\
\hline $\mathrm{EC} 42$ & 59 & EM & $\mathrm{Ib}$ & G1 & $\mathrm{U}$ \\
\hline EC43 & 55 & $\mathrm{AS}$ & $\mathrm{IVb}$ & G2 & $\mathrm{U}$ \\
\hline $\mathrm{EC} 44$ & 54 & EM & IIa & G1 & $\mathrm{U}$ \\
\hline $\mathrm{EC} 45$ & 78 & EM & $\mathrm{Ib}$ & G3 & $\mathrm{U}$ \\
\hline EC46 & 65 & EM & $\mathrm{Ib}$ & G2 & $\mathrm{M}$ \\
\hline EC47 & 68 & EM & IIIc & G3 & $\mathrm{U}$ \\
\hline EM48 & 54 & EM & IIIc & G2 & $\mathrm{U}$ \\
\hline EM49 & 60 & EM & $\mathrm{Ib}$ & G1 & $\mathrm{U}$ \\
\hline EC50 & 70 & EM & $\mathrm{IVb}$ & G2 & $\mathrm{U}$ \\
\hline
\end{tabular}

EC, endometrial cancer; EM, endometrioid adenocarcinoma; AS, adenosquamous carcinoma; G1, well-differentiated; G2, moderately differentiated; G3, poorly differentiated; M, methylated; U, unmethylated.
Table III. Frequency of aberrant DNA hypermethylation of CHFR in cells of normal endometrium and atypical endometrial hyperplasia.

\begin{tabular}{llll}
\hline No. & Age & Tissue type & CHFR \\
\hline AE1 & 30 & AEH & $\mathrm{U}$ \\
AE2 & 32 & AEH & $\mathrm{U}$ \\
AE3 & 35 & AEH & $\mathrm{U}$ \\
AE4 & 35 & AEH & $\mathrm{U}$ \\
AE5 & 46 & AEH & $\mathrm{U}$ \\
AE6 & 41 & AEH & $\mathrm{U}$ \\
AE7 & 50 & AEH & $\mathrm{U}$ \\
AE8 & 45 & AEH & $\mathrm{U}$ \\
AE9 & 47 & AEH & $\mathrm{U}$ \\
AE10 & 45 & AEH & $\mathrm{U}$ \\
NE1 & 51 & Sec & $\mathrm{U}$ \\
NE2 & 52 & Sec & $\mathrm{U}$ \\
NE3 & 44 & Sec & $\mathrm{U}$ \\
NE4 & 23 & Sec & $\mathrm{U}$ \\
NE5 & 34 & Sec & $\mathrm{U}$ \\
NE6 & 43 & Pro & $\mathrm{U}$ \\
NE7 & 42 & Pro & $\mathrm{U}$ \\
NE8 & 44 & Pro & $\mathrm{U}$ \\
NE9 & 32 & Pro & $\mathrm{U}$ \\
\hline
\end{tabular}

$\mathrm{AE}$, atypical endometrial hyperplasia; NE, normal endometrium; AEH, atypical endometrial hyperplasia; Sec, secretory phase; Pro, proliferative phase; $\mathrm{U}$, unmethylated.

Table IV. Correlation of aberrant DNA hypermethylation of CHFR with histological differentiation, stage at surgery and mean onset age.

\begin{tabular}{lccc}
\hline & \multicolumn{2}{c}{ CHFR } & \\
\cline { 2 - 3 } & Methylated & Unmethylated & P-value \\
\hline G1 & 0 & 23 & \\
G2 & 2 & 11 & $<0.05$ \\
G3 & 4 & 10 & \\
Stage & & & \\
I & 3 & 22 & NS \\
II & 0 & 7 & \\
III & 3 & 2 & NS \\
IV & 0 & $57.4 \pm 10.34$ & \\
Mean onset age & $57.5 \pm 6.90$ & & \\
\hline G1, well-differentiated; G2, moderately differentiated; G3, poorly dif- & & \\
ferentiated. & & &
\end{tabular}

of $C H F R$, and RT-PCR analysis of $C H F R$ expression showed reduced mRNA levels in these cells (Fig. 2). Consistent with this observation, the SNG-II and HEC108 cells showed higher 
A

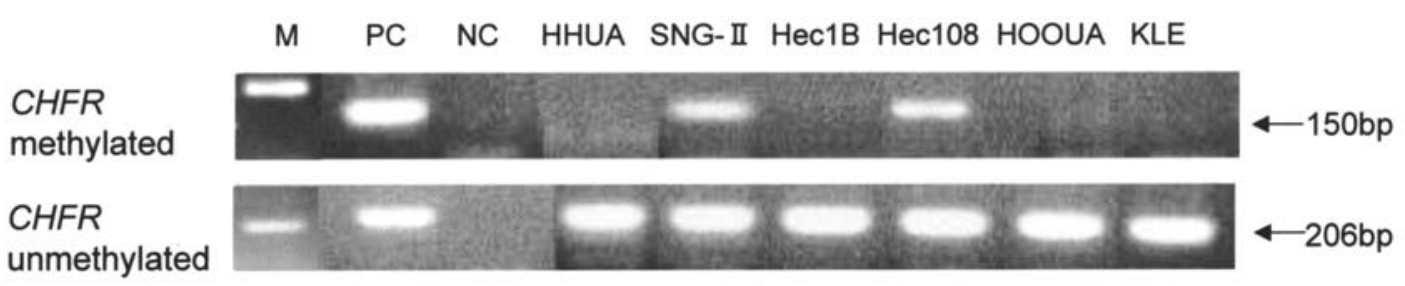

B

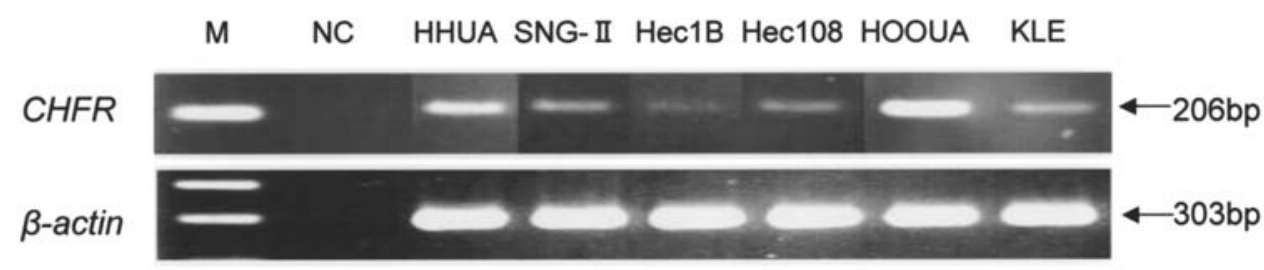

Figure 2. (A), MSP analysis of $C H F R$ in endometrial cancer-derived cell lines. Aberrant hypermethylation of $C H F R$ was found in two cell lines, SNG-II and HEC108. (B), Expression analysis of CHFR in endometrial cancer-derived cell lines using RT-PCR. CHFR expression was reduced in SNG-II and HEC108 cells, which showed aberrant hypermethylation of CHFR. M, marker; PC, positive control; NC, negative control.

Table V. Sensitivity (T/C ratio) of endometrial cancer-drived cells to various anticancer drugs in the CD-DST.

\begin{tabular}{lccccc}
\hline Cell line & CHFR & Cisplatin $(\%)$ & Doxorubicin $(\%)$ & Paclitaxel (\%) & Docetaxel (\%) \\
\hline HHUA & $\mathrm{U}$ & 100 & 100 & 22.5 & 31.0 \\
SNG-II & $\mathrm{M}$ & 52.0 & 65.1 & 16.7 & 15.1 \\
Hec1B & $\mathrm{U}$ & 91.1 & 85.7 & 71.2 & 65.9 \\
Hec108 & $\mathrm{M}$ & 56.6 & 76.6 & 11.8 & 20.6 \\
HOOUA & $\mathrm{U}$ & 94.2 & 88.4 & 20.7 & 50.9 \\
KLE & $\mathrm{U}$ & 57.6 & 93.6 & 60.8 & 63.9 \\
\hline
\end{tabular}

M, methylated; U, unmethylated.

sensitivity to paclitaxel and docetaxel in the CD-DST, compared to that of other cell lines (Table V).

Following treatment of SNG-II cells with 5-aza-dC, the aberrant hypermethylation band in the MSP analysis was weaker than that before administration of 5-aza-dC, and recovery of CHFR expression was shown in these cells (Fig. 3). Differences in sensitivity of SNG-II and HEC108 cells, and of KLE cells (which do not show aberrant hypermethylation of $C H F R$ ), to four anticancer drugs were examined using the CD-DST before and after 5-aza-dC administration. The $\mathrm{T} / \mathrm{C}$ ratios of cells treated with cisplatin and doxorubicin did not differ before and after 5-aza-dC administration, regardless of the presence or absence of aberrant hypermethylation of CHFR, showing that 5-aza-dC administration had no effect on sensitivity to cisplatin and doxorubicin. Similarly, the T/C ratios of KLE cells treated with paclitaxel and docetaxel were unchanged by 5 -aza-dC administration. However, the T/C ratios in SNG-II and HEC108 cells treated with paclitaxel and docetaxel significantly increased after 5-aza-dC administration, showing that these cells initially had low sensitivity to taxanes (Table VI).
Cell cycle changes in SNG-II and KLE cells treated with paclitaxel alone or combined paclitaxel and 5-aza-dC were determined using flow cytometry. The percentages of paclitaxel-treated KLE cells in the G2/M and Sub-G1 phases were 67.3 and $5.1 \%$, respectively; these data were almost the same as those for untreated control cells. KLE cells treated with paclitaxel and 5-aza-dC gave similar results. In contrast, the percentage of paclitaxel-treated SNG-II cells in the G2/M phase was very low $(0.2 \%)$ and the percentage of these cells in the Sub-G1 phase was higher (13.3\%) compared to control cells, indicating that paclitaxel administration induced apoptosis. However, with combined paclitaxel and 5-aza-dC treatment, the percentage of SNG-II cells in the G2/M phase was high $(82.7 \%)$ and that for cells in the Sub-G1 phase was low $(1.8 \%)$ compared to control cells; a similar pattern to that seen for paclitaxel-treated KLE cells (Fig. 4).

MSP analysis indicated aberrant hypermethylation of CHFR in $12.0 \%(6 / 50)$ of endometrial cancer specimens, with this being particularly common for G3 specimens $(4 / 14$, $28.6 \%$ ). Immunohistochemical analysis was conducted on specimens showing aberrant hypermethylation of CHFR from 
A
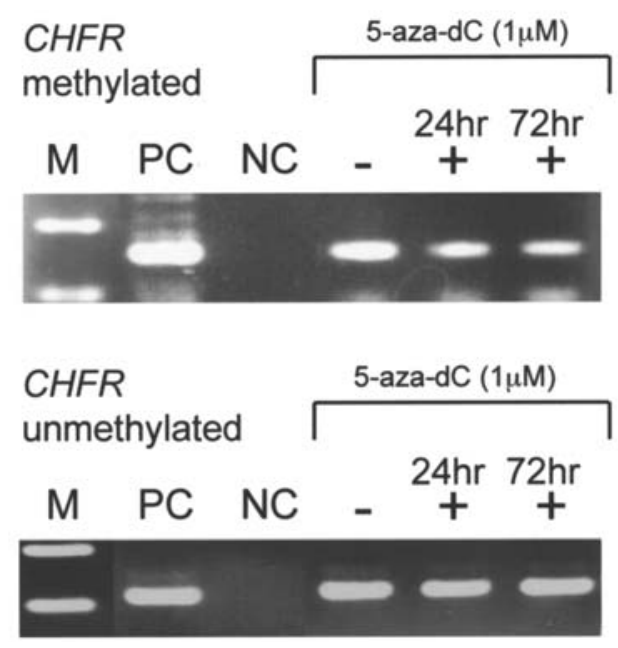

B

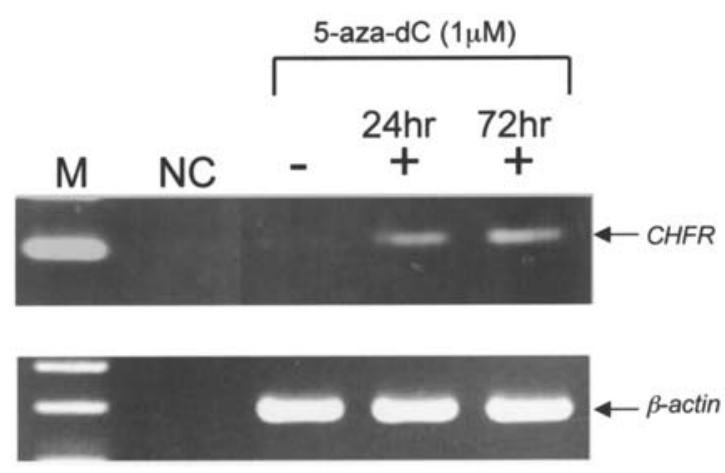

Figure 3. Demethylation analysis of CHFR in SNG-II cells. (A), In MSP, bands due to aberrant hypermethylation reduced with time after 5-aza-dC administration. (B), RT-PCR analysis showed recovered CHFR expression $24 \mathrm{~h}$ after the second 5-aza-dC administration. M, marker; PC, positive control; $\mathrm{NC}$, negative control.

Table VI. Changes in sensitivity ( $\mathrm{T} / \mathrm{C}$ ratio) of endometrial cancer-drived cells to various anticancer drugs after treatment with a demethylating agent.

\begin{tabular}{|c|c|c|c|c|c|c|c|c|c|}
\hline \multirow[b]{2}{*}{ Cell line } & \multirow[b]{2}{*}{ CHFR } & \multicolumn{2}{|c|}{ Cisplatin (\%) } & \multicolumn{2}{|c|}{ Doxorubicin (\%) } & \multicolumn{2}{|c|}{ Paclitaxel (\%) } & \multicolumn{2}{|c|}{ Docetaxel (\%) } \\
\hline & & $5-a z a(-)$ & $5-\operatorname{aza}(+)$ & 5-aza(-) & $5-\operatorname{aza}(+)$ & $5-a z a(-)$ & $5-a z a(+)$ & $5-a z a(-)$ & $5-\operatorname{aza}(+)$ \\
\hline SNG-II & M & 52.0 & 66.6 & 65.1 & 80.5 & 16.7 & 60.8 & 15.1 & 61.5 \\
\hline Hec108 & M & 56.6 & 64.6 & 76.6 & 76.7 & 11.8 & 70.7 & 20.6 & 69.4 \\
\hline KLE & $\mathrm{U}$ & 57.6 & 64.5 & 93.6 & 100 & 60.8 & 75.2 & 63.9 & 72.9 \\
\hline
\end{tabular}

5-aza, 5-aza-dC; M, methylated; U, unmethylated.

four G3 patients, and $75.0 \%$ (3/4) of these specimens showed reduced CHFR expression (Fig. 5). To investigate the relationship of sensitivity to paclitaxel with aberrant hypermethylation of $C H F R, 12$ surgical specimens of endometrial cancer were examined using CD-DST. The T/C ratio of specimens showing aberrant hypermethylation of $C H F R$ was the lowest (37.6\%), and these specimens exhibited higher sensitivity to paclitaxel compared to specimens without aberrant hypermethylation (Table VII).

\section{Discussion}

Aberrant hypermethylation of CHFR has been reported in gastrointestinal and lung cancers (7-9), but has not been examined in gynecologic cancer. Furthermore, the relationship between aberrant hypermethylation of CHFR and biological and disease characteristics has not been examined in any cancer. Our results indicate that aberrant hypermethylation of $C H F R$ occurs in G3 adenocarcinoma significantly more frequently than in $\mathrm{G} 1$ adenocarcinoma $(\mathrm{p}<0.05,28.6 \%)$.
It is known that $C H F R$ negatively regulates Aurora-A mitotic kinase: Aurora- $A$ is induced by inhibition of expression of CHFR (10), and overexpression of Aurora-A has been shown to induce chromosomal instability (CI) in various cancers (11-13). Since CI in endometrial cancer is commonly found in G3 adenocarcinoma (65\%) (14), it is likely that aberrant hypermethylation of CHFR is one cause of induction of CI in endometrial cancer. In addition, a relationship between aberrant hypermethylation of $C H F R$ and $h M L H 1$ has been reported in colon cancer (15), and aberrant hypermethylation of $h M L H 1$ has also been found in approximately $40 \%$ of endometrial cancers and is thought to be involved in the early stage of carcinogenesis $(16,17)$.

In cell cycle analysis using flow cytometry in endometrial cancer-derived cell lines, cells with a normal CHFR gene showed cell accumulation in $\mathrm{G} 2 / \mathrm{M}$ phase after paclitaxel administration. In contrast, in cells with $C H F R$ inactivated by aberrant hypermethylation, cell accumulation in $\mathrm{G} 2 / \mathrm{M}$ phase was not observed after paclitaxel administration but was found after combined treatment with paclitaxel and a demethylating 

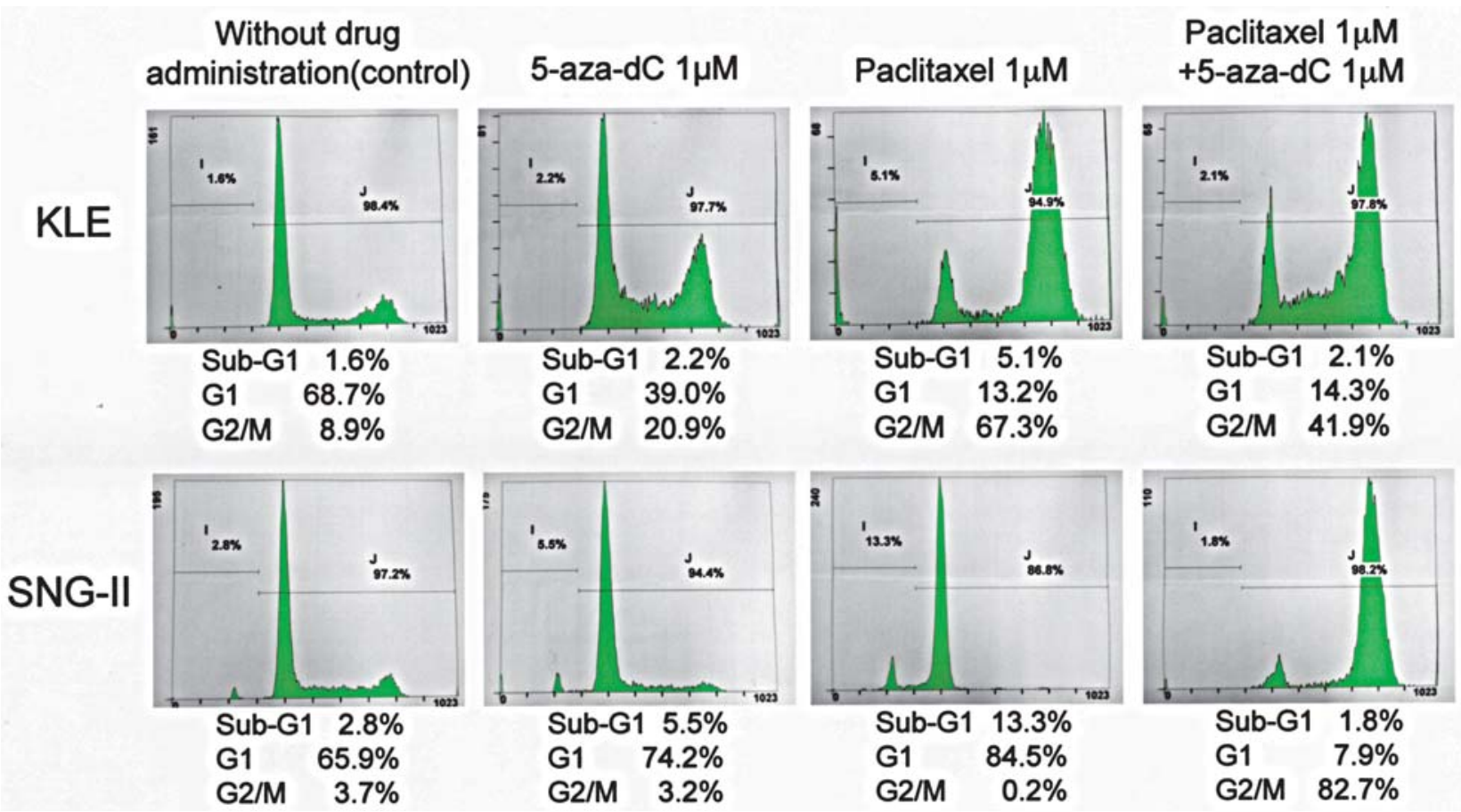

Figure 4. Cell cycle analysis in KLE and SNG-II cells using flow cytometry. KLE cells treated with paclitaxel alone and with combined paclitaxel and 5-aza$\mathrm{dC}$ showed cell accumulation in G2/M phase and no significant change in the number of cells in Sub-G1 phase. SNG-II cells treated with paclitaxel alone exhibited no cell accumulation in G2/M phase, but an increased number of cells in Sub-G1 phase; however, SNG-II cells treated with combined paclitaxel and 5-aza-dC showed significant cell accumulation in G2/M phase and a low number of cells in Sub-G1 phase, similarly to the controls.
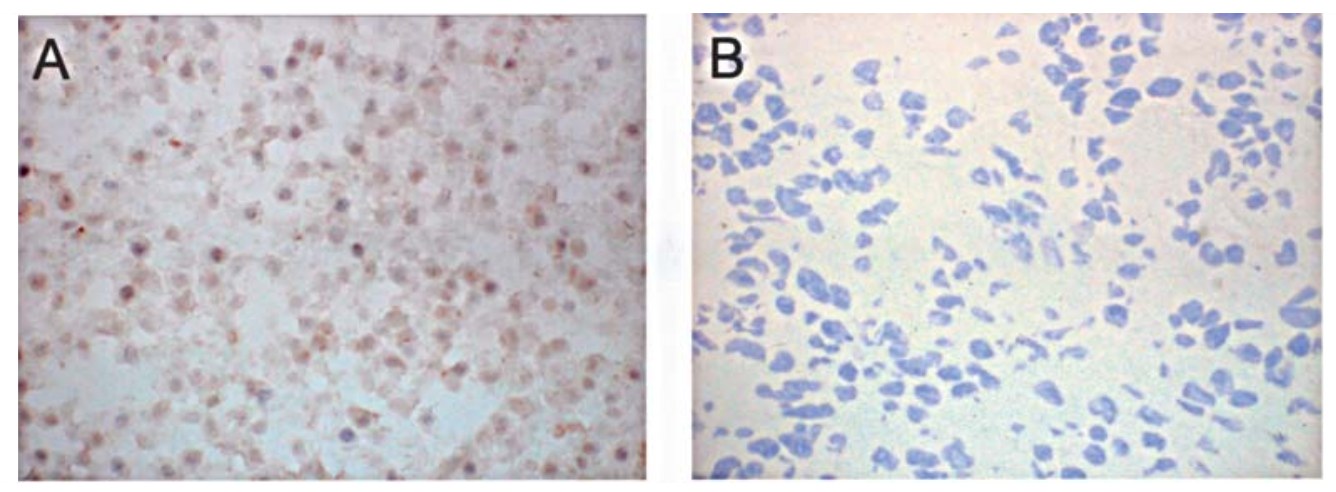

Figure 5. Immunohistochemical analysis of CHFR protein expression in patients with endometrioid adenocarcinoma (G3) with aberrant hypermethylation of CHFR. (A), EC35 staining; (B), EC32 staining. The nuclei of one of the four G3 adenocarcinoma patients stained positively (A), but three patients had nuclei with reduced staining $(\mathrm{B})$.

agent. These results suggest that cells with normal $C H F R$ undergo G2 arrest and can repair damage when the cells are treated with taxanes, thereby exhibiting resistance to taxanes, whereas cells with $C H F R$ inactivated by aberrant hypermethylation cannot detect damage and enter mitosis, thereby showing high sensitivity to taxanes. Based on the increased number of cells in Sub-G1 phase without accumulation of G2/M cells after paclitaxel administration, the high taxane sensitivity of cells with inactivated CHFR appears to be due to mitotic catastrophe causing cell death after entry into the mitotic phase.

Cells with aberrant hypermethylation of CHFR showed greatly decreased sensitivity to paclitaxel in the CD-DST after demethylation treatment. Although 5-aza-dC adminis- tration will result in demethylation of many genes, in addition to $C H F R$, sensitivity to cisplatin or doxorubicin was unaltered after demethylation, whereas sensitivity to paclitaxel and docetaxel increased, suggesting that aberrant hypermethylation of $C H F R$ is of importance in sensitivity to taxanes. Thus, aberrant hypermethylation of $C H F R$ is a potential index for prediction of cell sensitivity to taxanes.

The CD-DST is an anticancer drug sensitivity test in which tumor cells are cultured three-dimensionally. This method requires only a small number of cells and both culture cell lines and tumor tissues can be analyzed in the same experimental system. Use of the CD-DST for gynecologic cancer has been reported (6), and here we used the CD-DST in analysis of taxane sensitivity of clinical specimens of 
Table VII. Aberrant hypermethylation of CHFR and sensitivity (T/C ratio) of speciments of endometrial cancer to paclitaxel.

\begin{tabular}{llllll}
\hline No. & $\begin{array}{c}\text { Tissue } \\
\text { type }\end{array}$ & Stage & Differentiation & CHFR & $\begin{array}{c}\text { T/C } \\
\text { ratio (\%) }\end{array}$ \\
\hline EC30 & AS & Ib & G1 & U & 84.0 \\
EC31 & EM & Ib & G2 & U & 79.6 \\
EC32 & EM & IIIc & G3 & M & 37.6 \\
EC33 & EM & Ib & G2 & U & 86.9 \\
EC36 & AS & IIIc & G3 & U & 59.8 \\
EC37 & EM & Ic & G3 & U & 38.2 \\
EC38 & AS & IIIc & G1 & U & 66.4 \\
EC39 & EM & Ic & G1 & U & 100 \\
EC47 & EM & IIIc & G3 & U & 100 \\
EC48 & EM & IIIc & G2 & U & 84.3 \\
EC49 & EM & Ib & G1 & U & 79.7 \\
EC50 & EM & IVb & G2 & U & 70.3 \\
\hline
\end{tabular}

EC, endometrial cancer; EM, endometrioid adenocarcinoma; AS, adenosquamous carcinoma; G1, well-differentiated; G2, moderately differentiated; G3, poorly differentiated; M, methylated; U, unmethylated.

endometrial cancer. The CD-DST results for 12 specimens of endometrial cancer showed that cells with aberrant hypermethylation of $C H F R$ had high sensitivity to paclitaxel, as also found in cultured cells; this is the first such study of this relationship in endometrial cancer. Immunohistochemical analysis showed that of four patients with G3 adenocarcinoma with aberrant hypermethylation of $C H F R$, three exhibited reduced expression of CHFR protein. This result indicates that aberrant hypermethylation of CHFR is involved in reduced protein expression in vivo. Overall, our results suggest a new strategy for design of personalized medicine for endometrial cancer using the hypermethylation status of CHFR as a molecular index. This strategy may be particularly important in treatment of G3 adenocarcinoma, since it is known to have a poor prognosis.

\section{Acknowledgements}

This study was partially supported by the Ministry of Education, Culture, Sports, Science and Technology through a Grant-in-Aid for Young Scientists (B) (17791135), and by the Haraguchi Memorial Cancer Fund charitable trust, and by Keio University Grant-in-Aid for Encouragement of Young Medical Scientists. We are grateful to Cytyc Corp. for provision of ThinPrep.

\section{References}

1. Suzuki H, Itoh F, Toyota M, Kikuchi T, Kakiuchi H and Imai K: Inactivation of the 14-3-3 sigma gene is associated with 5' CpG island hypermethylation in human cancers. Cancer Res 60: 4353-4357, 2000.
2. Satoh A, Toyota M, Itoh F, Sasaki Y, Suzuki H, Ogi K, Kikuchi T, Mita H, Yamashita T, Kojima T, Kusano M, Fujita M, Hosokawa M, Endo T, Tokino T and Imai K: Epigenetic inactivation of CHFR and sensitivity to microtubule inhibitors in gastric cancer. Cancer Res 63: 8606-8613, 2003.

3. Scolnick DM and Halazonetis TD: Chfr defines a mitotic stress checkpoint that delays entry into metaphase. Nature 406: 430-435, 2000.

4. Toyota M, Sasaki Y, Satoh A, Ogi K, Kikuchi T, Suzuki H, Mita H, Tanaka N, Itoh F, Issa JP, Jair KW, Schuebel KE, Imai T and Tokino T: Epigenetic inactivation of CHFR in human tumors. Proc Natl Acad Sci USA 100: 7818-7823, 2003

5. Susumu N, Aoki D, Noda T, Nagashima Y, Hirao T, Tamada Y, Banno K, Suzuki A, Suzuki N, Tsuda H, Inazawa J and Nozawa S: Diagnostic clinical application of two-color fluorescence in situ hybridization that detects chromosome 1 and 17 alterations to direct touch smear and liquid-based thin-layer cytologic preparations of endometrial cancers. Int J Gynecol Cancer 15: 70-80, 2005.

6. Kawaguchi M, Banno K, Susumu N, Yanokura M, Kuwabara Y, Hirao N, Tsukazaki K and Nozawa S: Successful analysis of anticancer drug sensitivity by CD-DST using pleural fluid and ascites from patients with advanced ovarian cancer: case reports. Anticancer Res 25: 3547-3551, 2005.

7. Tokunaga E, Oki E, Nishida K, Koga T, Yoshida R, Ikeda K, Kojima A, Egashira A, Morita N, Kakeji Y and Maehara Y: Aberrant hypermethylation of the promoter region of the CHFR gene is rare in primary breast cancer. Breast Cancer Res Treat 97: 199-203, 2006.

8. Corn PG, Summers MK, Fogt F, Virmani AK, Halazonetis TD and EL-Deiry WS: Frequent hypermethylation of the $5^{\prime} \mathrm{CpG}$ island of the mitotic stress checkpoint gene Chfr in colorectal and non-small cell lung cancer. Carcinogenesis 24: 47-51, 2003.

9. Mizuno K, Osada H, Konishi H, Tatematsu Y, Yatabe Y, Mitsudomi T, Fujii Y and Takahashi T: Aberrant hypermethylation of the CHFR prophase checkpoint gene in human lung cancers. Oncogene 21: 2328-2333, 2002.

10. Yu X, Minter-Dykhouse K, Malureanu L, Zhao WM, Zang D, Merkle CJ, Ward JM, Saya H, Fang G, van Deursen J and Chen J: Chfr is required for tumor suppression and Aurora A regulation. Nat Genet 37: 401-406, 2005.

11. Hu W, Kavanagh JJ, Deaver M, Johnston DJ, Freedman RS, Verschraegen CF and Sen S: Frequent overexpression of STK15/ Aurora-A/BTAK and chromosomal instability in tumorigenic cell cultures derived from human ovarian cancer. Oncol Res 15: 49-57, 2005.

12. Li JJ, Weroha SJ, Lingle WL, Papa D, Salisbury JL and Li SA: Estrogen mediates Aurora-A overexpression, centrosome amplification, chromosomal instability, and breast cancer in female ACI rats. Proc Natl Acad Sci USA 101: 18123-18128, 2004.

13. Fraizer GC, Diaz MF, Lee IL, Grossman HB and Sen S: Aurora-A/STK15/BTAK enhances chromosomal instability in bladder cancer cells. Int J Oncol 25: 1631-1639, 2004.

14. Hirasawa A, Aoki D, Inoue J, Imoto I, Susumu N, Sugano K, Nozawa $S$ and Inazawa J: Unfavorable prognostic factors associated with high frequency of microsatellite instability and comparative genomic hybridization analysis in endometrial cancer. Clin Cancer Res 9: 5675-5682, 2003.

15. Brandes JC, van Engeland M, Wouters KA, Weijenberg MP and Herman JG: CHFR promoter hypermethylation in colon cancer correlates with the microsatellite instability phenotype. Carcinogenesis 26: 1152-1156, 2005.

16. Esteller M, Catasus L, Matias-Guiu X, Mutter GL, Parat J, Baylin SB and Herman JG: hMLH1 promoter hypermethylation is an early event in human endometrial tumorigenesis. Am J Pathol 155: 1767-1772, 1999.

17. Kanaya T, Kyo S, Maida Y, Yatabe N, Tanaka M, Nakamura M and Inoue M: Frequent hypermethylation of MLH1 promoter in normal endometrium of patients with endometrial cancers. Oncogene 22: 2352-2360, 2003. 